\title{
An Independent and External Validation of the ACC NCDR Bleeding Risk Score among a National Multi-Site Community Hospital Registry of Cardiac Interventions
}

\author{
David R. Dobies ${ }^{1}$, Kimberly R. Barber ${ }^{2, *}$ and Amanda L. Cohoon ${ }^{3}$ \\ ${ }^{1}$ Regional Cardiology Associates, Grand Blanc, MI, USA \\ ${ }^{2}$ Genesys Regional Medical Center, Office of Research, Grand Blanc, MI, USA \\ ${ }^{3}$ Genesys Regional Medical Center, Cardiac Cath Lab, Grand Blanc, MI, USA
}

\begin{abstract}
Background: An accurate tool with good discrimination for bleeding would be useful to clinicians for improved management of all their patients. Bleeding risk models have been published but not externally validated in independent clinical dataset. We chose the NCDR PCI score to validate within a large, multi-site community datasets. The aim of the study was to determine the diagnostic utility of this bleeding risk score tool.

Methods: This is a large-scale retrospective analysis utilizing American College of Cardiology data from a 37-hospital health system. The central repository of $\mathrm{PCl}$ procedures between 6-1-2009 and 6-30-2012 was utilized to validate the NCDR PCl bleeding risk score (BRS) among 4693 patients. The primary endpoint was major bleeding. Discriminant analysis calculating the receiver operating characteristic curve was performed.

Results: There were $143(3.0 \%)$ major bleeds. Mean bleeding risk score was 14.7 (range $3-42$ ). Incidence of bleeding by risk category: low $(0.5 \%)$, intermediate $(1.7 \%)$, and high risk (7.6\%). Patients given heparin had $113(3.7 \%)$ major bleeds and those given bivalirudin had $30(2.1 \%)$ major bleeds. Tool accuracy was poor to fair (AUC 0.78 heparin, 0.65 bivalirudin). Overall accuracy was 0.71 ( $\mathrm{Cl}: 0.66-0.76)$. Accuracy did not improve when confined to just the intermediate risk group (AUC 0.58; Cl: 0.55-0.67).

Conclusion: Bleeding risk tools have low predictive value. Adjustment for anticoagulation use resulted in poor discrimination because bivalirudin differentially biases outcomes toward no bleeding. The current state of bleeding risk tools provides little support for diagnostic utility in regards to major bleeding and therefore have limited clinical applicability.
\end{abstract}

Keywords: Major bleeding, bleeding risk model, anticoagulant, percutaneous coronary intervention, cardiovascular.

\section{INTRODUCTION}

Interest in bleeding risk stratification for patients undergoing percutaneous coronary artery intervention $(\mathrm{PCl})$ has proliferated with a corresponding increase in multiple and competing quantitative tools for assessing bleeding risk in patients [1-6]. Preventing major bleeding events following $\mathrm{PCl}$ is extremely important because such bleeding is known to have a significant impact on patient outcomes. Those who experience a $\mathrm{PCl}$-related major bleed have increased morbidity [710], additional imaging and longer hospital stays [11]. They also have a 3-fold increase in mortality [12].

An accurate tool with bleeding risk discriminative ability would be useful to clinicians for improved management of all their patients. Articles have been published on the development of several tools for predicting bleeding risk $[3,13-16]$. Many have yet to be externally validated among a real-world, wide spectrum of patients. Despite this, there is advocacy for bleeding risk stratification to potentially guide anticoagulant

*Address correspondence to this author at the Genesys Regional Medical Center, Office of Research / Ste 2442, One Genesys Pkwy, Grand Blanc, MI 48439, USA; Tel: 810-606-7724; Fax: 810-606-5882;

E-mail: kbarber@genesys.org utilization. The implication is that different anticoagulants can be targeted based on bleeding risk. How accurate these risk scores are when validated in a real world clinical practice has not been fully determined. There is a need for a clinically focused validation analysis of these bleeding risk scores in current, real-world clinical patients.

We chose a nationally recognized index, the National Cardiovascular Data Registry of Percutaneous Coronary Interventions (NCDR PCl) Bleeding Risk Score [13], to be validated by a large, independent, multi-site community hospital real-world data registry. This bleeding risk index was chosen because of its current use among hospitals, including Accountable Care Organization (ACO) sites in the United States. The hypothesis was to test the discriminatory power of the NCDR PCI bleeding risk tool and to determine the tool's diagnostic utility among patients undergoing $\mathrm{PCl}$.

\section{METHODS}

\section{Study Design and Population}

This is a real-world, large-scale retrospective analysis utilizing American College of Cardiology 
(ACC) data from a 37-hopsital National Health System. A central repository, independent of the NCDRCathPCl database, was prospectively initiated across the health system in 2007 with mandatory reporting of 84 well-established data points defined by the ACC. Data were entered prospectively by trained personnel at the time of the heart catheterization for consecutive patients from all hospitals performing catheterization in this healthcare system. Cath lab technicians and nursing staff enter the data immediately following each procedure. The registry represents procedures and devices as used in routine clinical practice per operator discretion. The database is routinely audited for accuracy and completeness. The data from the most recent three-year period from June 1, 2009 through June 30, 2012 for index $\mathrm{PCl}$ procedures was selected $(n=5114)$. Pre-procedure creatinine values were used for the GFR calculation. Patients missing preprocedure creatinine $(n=254)$ had post-procedure creatinine imputed into the calculation. An additional 167 patients had missing pre and post creatinine and were excluded from the analysis (3.2\%). Patients with complete bleeding risk score information were included in this study $(n=4693)$.

\section{Endpoints}

The primary endpoint for the predictive accuracy of the NCDR PCI Bleeding Risk Score (BRS) was major bleeding episodes. Major bleeding was defined as any of the following occurring within a 72 hour period of the procedure: hemoglobin drop of $>=3 \mathrm{~g} / \mathrm{dL}$; transfusion of whole blood or packed red blood cells; procedural intervention/surgery at the bleeding site to reverse/stop or correct the bleeding.

\section{Bleeding Risk Model}

The risk scale used for this propensity analysis was the NCDR PCI Bleeding Risk Score [17]. The 13-point (13 pt) scale includes the prognostic factors of Acute Coronary Syndrome (ACS) type (10 or $3 \mathrm{pt}$ ), NYHA Class IV CHF status (4 pt), gender $\left(\begin{array}{lll}6 & \mathrm{pt}\end{array}\right)$, cardiovascular history $(8,4$, or $2 \mathrm{pt})$, no previous $\mathrm{PCl}(4$ pt), age $(8,5$, or $2 \mathrm{pt})$ and estimated GFR (1 pt per 10 unit decrease <90). The risk score is further categorized into three distinct risk levels of low $(\leq 7 \mathrm{pt})$, intermediate (8-16 pt), and high ( $\geq 17 \mathrm{pt})$. Continuous variables are presented as means (standard deviations) and categorical variables are presented as counts (\%) and compared by $X^{2}$ analysis and Fischer Exact test for rare event rates. The bleeding risk score
(BRS) was calculated for each patient in the database from the prognostic variables and programmed into SPSS. The Modification of Diet in Renal Disease (MDRD) equation was used to calculate the GFR $(\mathrm{mls} / \mathrm{min} / 1.73 \mathrm{~m} 2)$ from the pre-procedure creatinine $(\mathrm{mg} / \mathrm{dl})$ levels reported in the registry and the following formula was imputed into the database (186 $x$ (creatinine/88.4 $)^{-1.154} \times(\text { age })^{-0.203} \times(0.742$ if female $) \times$ (1.210 if black) [18]. Creatinine levels were those that were the most recent creatinine level obtained between the procedure and one month prior to the procedure. The actual BRS was calculated and then constructed to assign patients into three risk categories (low, intermediate, and high). Patients were further categorized by cutoff values ( $\leq 7$ and $8-16$ ) with the low and intermediate risk combined and the high risk category $(\geq 17)$ used as the comparative group for sensitivity and accuracy analyses.

\section{Statistical Analysis}

Discriminant analysis was conducted and evaluated for each risk category. Discrimination of the scale was evaluated by the receiver operating characteristics (ROC) curve and area-under-the curve (AUC) expressed by the $c$-statistic. Calibration or level of agreement between observed and predicted outcomes was assessed using the Hosmer-Leme show goodness-of-fit test. For all analyses, significance was set at $p<0.05$. Software for processing the data was SPSS 18.0 (Chicago, Illinois, USA).

\section{RESULTS}

\section{Baseline Characteristics are Summarized in Table 1}

Of the total number of patients ( $n=4693)$, a majority were Caucasian $(n=4259,90.8 \%)$ and male $(n=3139$, $66.9 \%)$. Most were hypertensive $(n=3964,84.6 \%)$ and overweight $(n=1633,35.3 \%)$ or obese $(n=2146$, $46.4 \%)$. Diabetes was present in $1728(36.8 \%)$. The mean age was $64.3(\mathrm{sd}=12.0)$. The overall mean creatinine level was $1.18(\mathrm{sd}=0.93$, range $0-20)$. The mean GFR level was 57.1 ( $\mathrm{sd}=26.3$, range: $2-818$ ).

There were 1889 (40.3\%) elective procedures and $2794(59.6 \%)$ urgent or emergent. The most common indication for percutaneous coronary intervention $(\mathrm{PCl})$ was high-risk non STEMI or unstable angina $(n=2064$, $44.0 \%$ ). A majority were conducted through femoral access ( $n=4546,97.1 \%)$ and with manual compression to close the site $(n=2884,78.7 \%)$. 
Table 1: Patient Characteristics for Total Sample ( $n=$ 4693)

\begin{tabular}{|l|c|}
\hline \multicolumn{1}{|c|}{ Variable } & Number (\%) \\
\hline \hline Gender: Male & $3139(66.9)$ \\
\hline Race: Caucasian & $4259(90.8)$ \\
\hline HTN & $3964(84.5)$ \\
\hline Smoker & $1434(30.6)$ \\
\hline Prior MI & $1491(31.8)$ \\
\hline Prior CHF & $657(14.0)$ \\
\hline Prior PCl & $2018(43.0)$ \\
\hline Prior CABG & $1023(21.8)$ \\
\hline Kidney Disease & $93(2.0)$ \\
\hline CVD & $618(13.2)$ \\
\hline PVD & $640(13.7)$ \\
\hline Lung Disease & $932(19.9)$ \\
\hline Death & $52(1.1)$ \\
\hline
\end{tabular}

\section{Endpoints}

A total of 143 patients (3.0\%) experienced a major bleeding event. Other post procedure events included $45(1.0 \%)$ cardiogenic shock, $63(1.3 \%)$ heart failure, $13(0.3 \%)$ cerebral vascular accident, $3 \quad(0.1 \%)$ hemorrhagic stroke, $4(0.1 \%)$ tamponade, $41(0.9 \%)$ other vascular complication, $12(0.3 \%)$ dialysis, and $123(2.6 \%)$ transfusions. There were $52(1.1 \%)$ predischarge deaths.

\section{Bleeding Risk Score}

A breakdown of patients with the factors included in the bleeding risk model is summarized in Table 2.

The categorical cutoff points for the NCDR BRS placed a majority of patients into the "Intermediate" risk category $(n=2404,51.2 \%)$. The mean bleeding risk score was 14.7 ( $s d=5.9$, range: 3 - 42). The incidence of bleeding observed for the low, intermediate, and high risk categories was $0.5 \%, 1.7 \%$, and $7.6 \%$ respectively. There were 113 of $3080(3.7 \%)$ bleeding events in the heparin group and 30 of $1464(2.1 \%)$ bleeding events in the bivalirudin group. Among patients receiving heparin, with or without $\mathrm{Ilb} / \mathrm{llla}$ inhibitors, the rates according to risk category were $0.3 \%, 1.7 \%$, and $8.7 \%$ respectively. Among patients receiving bivalirudin the rates were $0.7 \%, 1.7 \%$, and $3.5 \%$. The BRS was a highly significant predictor of bleeding among patients who had received heparin $(\mathrm{OR}=5.5, \mathrm{Cl}: 3.7-8.1, \mathrm{p}<0.0001)$ but a weak predictor among those receiving bivalirudin $(\mathrm{OR}=2.1, \mathrm{Cl}: 1.1$ 3.8, $p=0.01$ ).

Table 2: Breakdown of Patient Factors per Bleeding Risk Score

\begin{tabular}{|c|c|c|}
\hline Variable & Points Assigned & Frequency n (\%) \\
\hline $\begin{array}{c}\text { ACS Type: } \\
\text { STEMI } \\
\text { Other }\end{array}$ & $\begin{array}{r}10 \\
3\end{array}$ & $\begin{array}{c}633(7.7) \\
4058(49.1)\end{array}$ \\
\hline Cardiogenic Shock & 8 & $68(0.8)$ \\
\hline Female Gender & 6 & $3167(38.3)$ \\
\hline Previous CHF & 5 & $1039(12.6)$ \\
\hline No Previous $\mathrm{PCl}$ & 4 & $5238(63.4)$ \\
\hline NYHA Class IV CHF & 4 & $84(1.0)$ \\
\hline PVD & 2 & $920(11.1)$ \\
\hline $\begin{array}{l}\text { Age: } \\
\qquad \begin{array}{l}66-75 \text { y } \\
76-85 \text { y } \\
>85 y\end{array}\end{array}$ & $\begin{array}{l}2 \\
5 \\
8\end{array}$ & $\begin{array}{c}2227(26.9) \\
1369(16.6) \\
201(2.4)\end{array}$ \\
\hline $\begin{array}{l}\text { Estimated GFR } \\
(1 \text { per } 10 \text { unit decrease }<90 \text { ) }\end{array}$ & $\begin{array}{r}0 \\
>0\end{array}$ & $\begin{array}{c}1799(1.9) \\
6464(78.2)\end{array}$ \\
\hline $\begin{array}{l}\text { Risk Categories: } \\
\qquad \begin{array}{l}\text { Low } \\
\text { Intermediate } \\
\text { High }\end{array}\end{array}$ & $\begin{array}{l}\leq 7 \\
8-16 \\
\geq 17\end{array}$ & $\begin{array}{l}2071(25.1) \\
4274(51.7) \\
1918(23.2)\end{array}$ \\
\hline
\end{tabular}


Table 3: Accuracy of the Bleeding Risk Score by Categories for Major Bleeding

\begin{tabular}{|c|c|c|c|c|}
\hline All & Positive Bleed & Negative Bleed & Total & Test Discrimination \\
\hline High Risk & 109 & 1617 & 1726 & \multirow{3}{*}{$\begin{array}{c}\text { Sensitivity } 0.76 \\
\text { Specificity } 0.64 \\
\text { PPV: } 6.3 \% \\
\text { NPV: } 98 \% \\
\text { +LR: } 2.1(\mathrm{Cl}: 1.7-2.8) \\
\text {-LR: } 0.3 \text { (Cl:0.2-0.7) }\end{array}$} \\
\hline Not High Risk & 34 & 2932 & 2966 & \\
\hline Total & 143 & 4549 & 4692 & \\
\hline \multicolumn{5}{|l|}{ Heparin Only } \\
\hline High Risk & 90 & 1107 & 1197 & \multirow{3}{*}{$\begin{array}{c}\text { Sensitivity } 0.80 \\
\text { Specificity } 0.59 \\
\text { PPV: } 7.5 \% \\
\text { NPV: } 98.7 \% \\
\text { +LR: } 1.9(\mathrm{Cl}: 1.8-2.2) \\
\text {-LR: } 0.3(\mathrm{Cl}: 0.2-0.5)\end{array}$} \\
\hline Not High Risk & 22 & 1631 & 1653 & \\
\hline Total & 112 & 2738 & 2850 & \\
\hline \multicolumn{5}{|l|}{ Bivalirudin Only } \\
\hline High Risk & 19 & 505 & 524 & \multirow{3}{*}{$\begin{array}{c}\text { Sensitivity } 0.65 \\
\text { Specificity } 0.61 \\
\text { PPV: } 3.6 \% \\
\text { NPV: } 98.7 \% \\
\text { +LR: } 1.6(\mathrm{Cl}: 1.3-2.2) \\
\text {-LR: } 0.5(\mathrm{Cl}: 0.3-0.9)\end{array}$} \\
\hline Not High Risk & 10 & 795 & 805 & \\
\hline Total & 29 & 1300 & 1329 & \\
\hline
\end{tabular}

\section{Diagnostic Utility}

Overall sensitivity was 0.76 and specificity was 0.64 . The positive Likelihood Ratio was 2.1 and the negative Likelihood Ratio was 0.38. Among patients receiving heparin the diagnostic values included; sensitivity (0.79), specificity (0.64), positive Likelihood Ratio (2.2) and negative Likelihood Ratio (0.33). Among patients receiving bivalirudin the diagnostic values included; sensitivity (0.63), specificity (0.65), positive Likelihood Ratio (1.8) and negative Likelihood Ratio (0.57). For both heparin and bivalirudin patients, the BRS demonstrated Likelihood ratios that provide indeterminate results (Table 3 ).

We also conducted a discriminate analysis on the BRS scale for prediction of major bleeding. Receiver Operator Characteristics were calculated and the corresponding curves generated. Determination of the additive value of the tool was made by the area under the curve (AUC) scale for which a 1.0 is a perfect test [19]. The ranking ranges are as follows: Excellent (.91 - 1.0), Good (.81 - .90), Fair (.71 - .80), Poor (.61 $.70)$, and Fail $(.51-.60)$.

Among the entire sample of 4693 patients, 143 (3.0\%) had a major bleeding outcome. The AUC was 0.71 (Cl: $0.67-0.79$ ), a prediction value of 'fair' for the BRS tool. We then examined the accuracy within each cutoff point of the bleeding risk score (low, intermediate, high) (Figure 1). The AUC for the Low Risk group of patients $(n=879$, events $=4)$ was 0.57 (Cl: $0.26-0.88)$, the AUC for the Intermediate Risk group $(n=2364$, events $=40)$ was $0.58(\mathrm{Cl}: 0.49-$ $0.67)$, and the AUC for the High Risk group ( $n=1306$, events=99) was 0.61 (Cl: $0.55-0.67)$. The corresponding predictive value for these risk levels is fair, fair, and poor, respectively.

Because the number of events for the low risk group was low $(n=4)$ we examined the BRS scale with a cutoff point of 17 for which the low and intermediate risk were combined. The AUC for this group ( $n=3243$, events = 44) was $0.64(\mathrm{Cl}: 0.57-0.72)$ or poor predictive value. We also examined the accuracy of the tool by anticoagulant subgroups (Figure 2). For the 3080 heparin patients, there were 113 bleeding events and the AUC was 0.78 (Cl: 0.74 - 0.82), a discriminating value of fair. For the 1464 bivalirudin patients, there were 30 bleeding events and the AUC was $0.65(\mathrm{Cl}: 0.56-0.75)$, a discriminating value of poor.

\section{DISCUSSION}

Validation of the NCDR PCl bleeding risk score (BRS) in this wide-spectrum population of current 


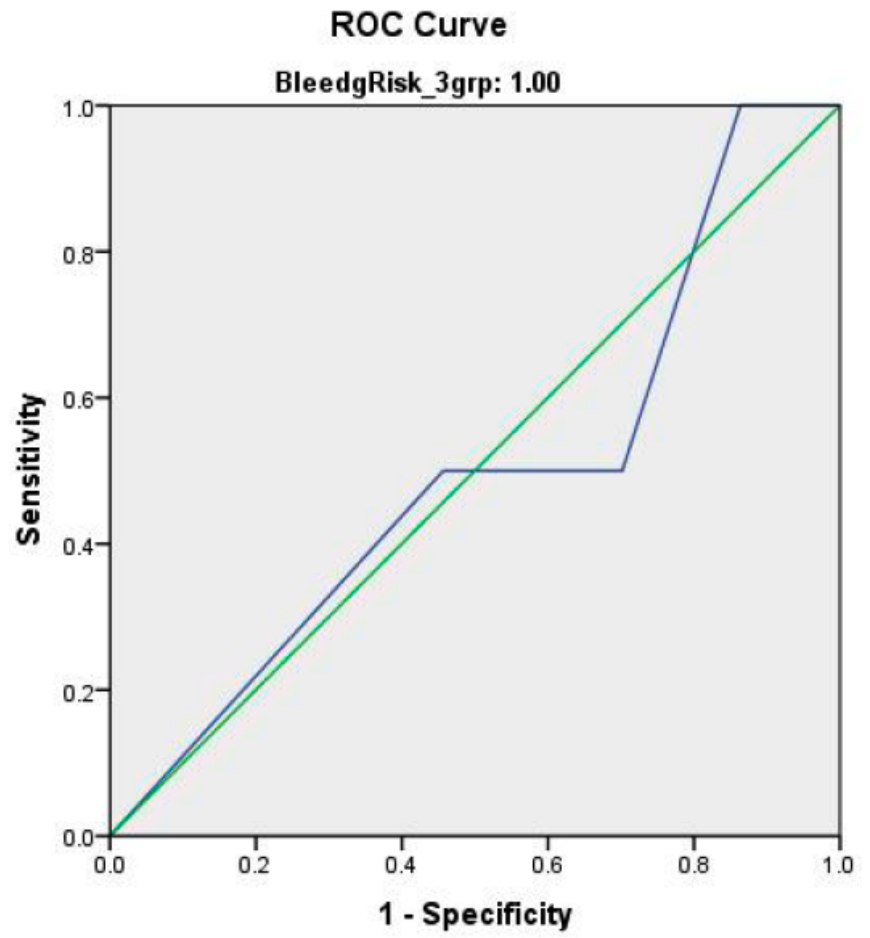

Diagonal segments are produced by ties

a

\section{ROC Curve}

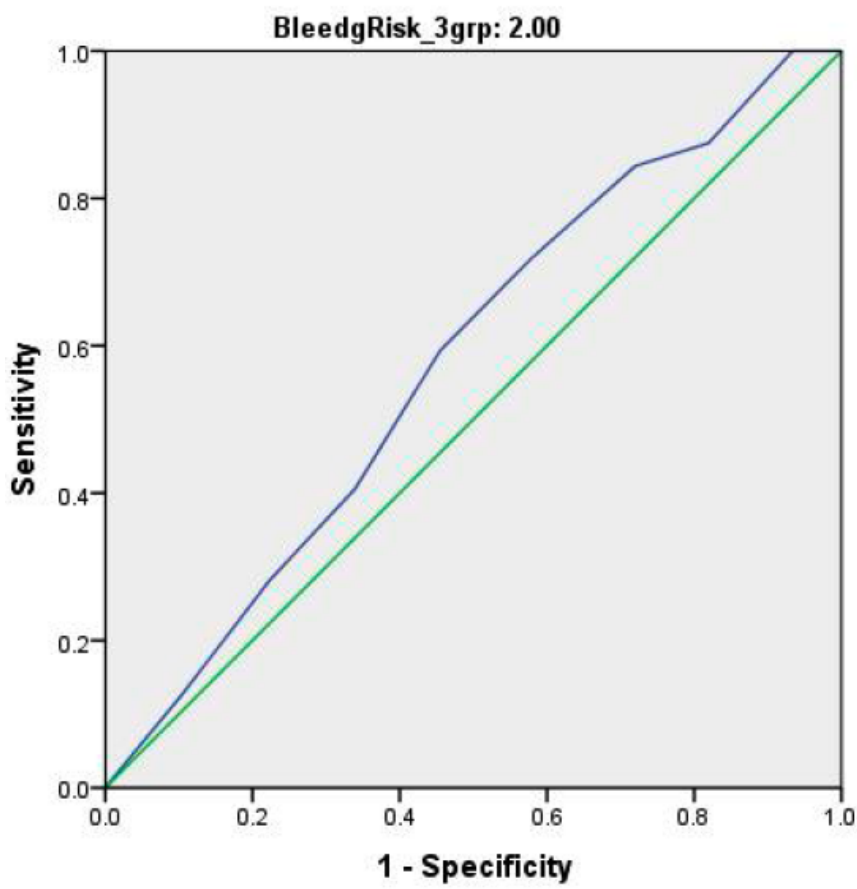

Diagonal segments are produced by ties.

b

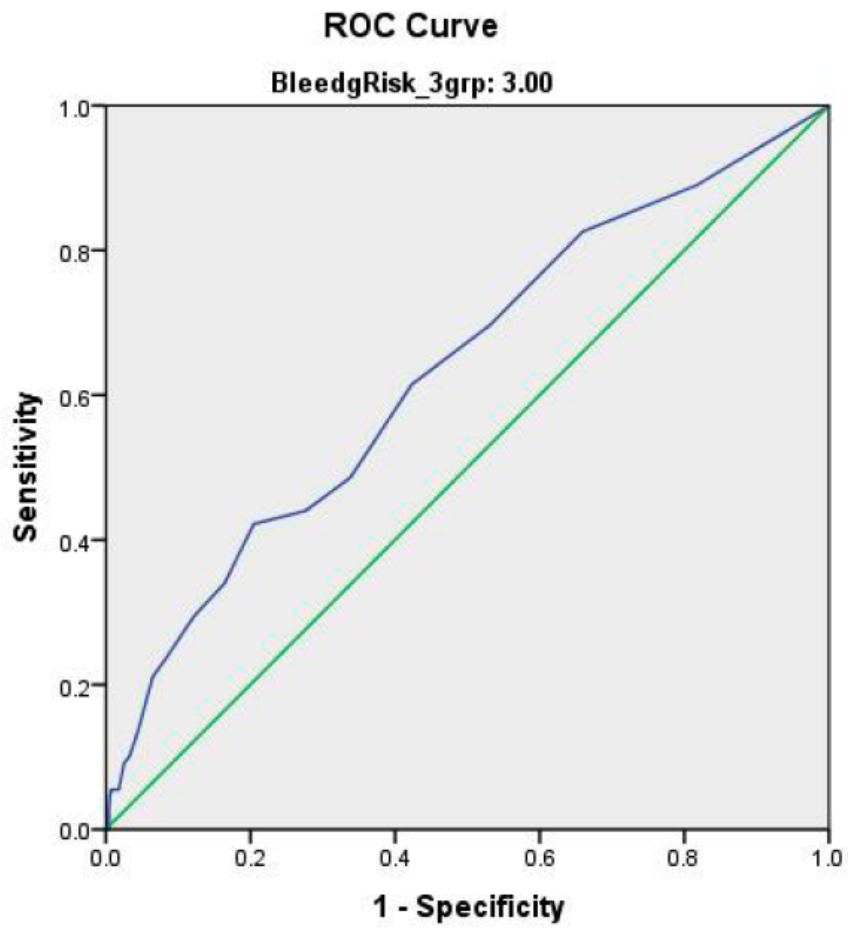

Diagonal segments are produced by ties.

c

Figure 1: a. ROC curve for low risk group (AUC=0.49, Cl:0.26 - 0.88). b. ROC curve for Intermediate risk (AUC=0.57, Cl:0.490.67). c. ROC curve for high risk (AUC=0.63, $\mathrm{Cl}: 0.55-0.67)$. 


\section{ROC Curve}

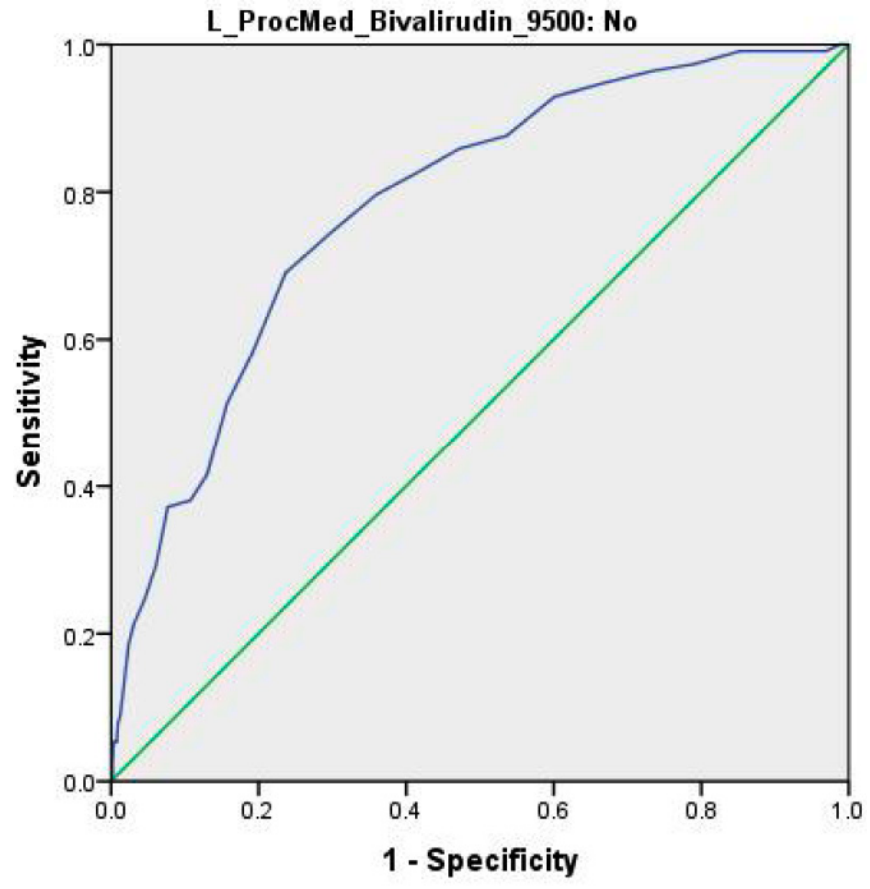

Diagonal segments are produced by ties

a

\section{ROC Curve}

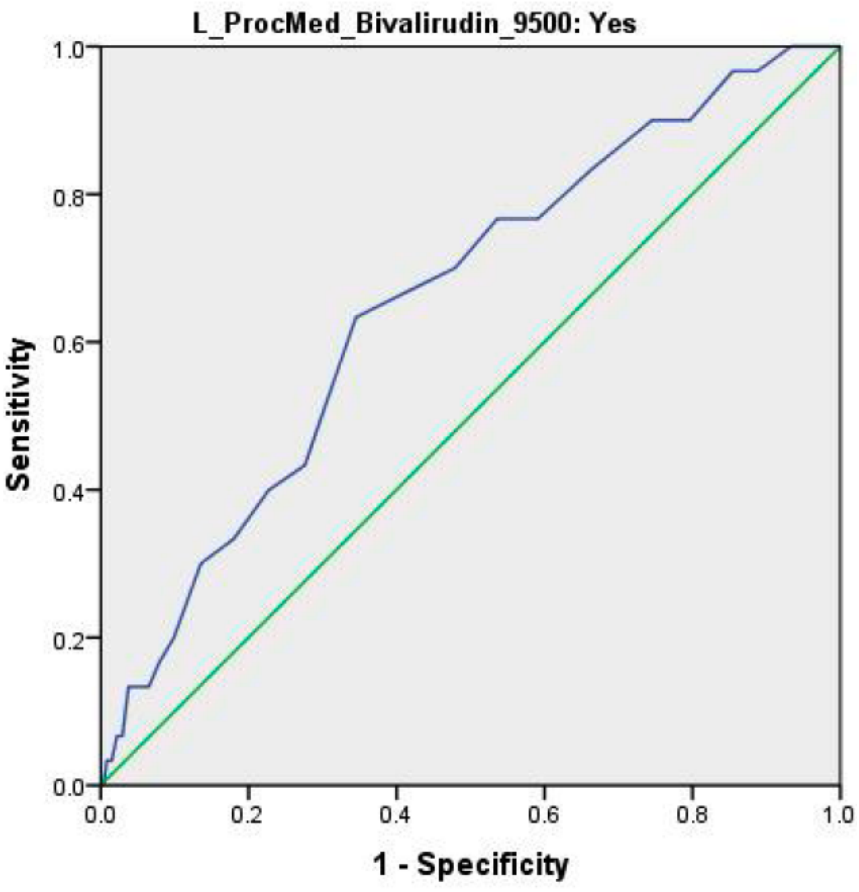

Diagonal segments are produced by ties.

b

Figure 2: a. ROC Curve for Heparin group $(\mathrm{AUC}=0.78, \mathrm{Cl}: 0.74-0.82)$. b. ROC Curve for Bivalirudin $(\mathrm{AUC}=0.65, \mathrm{Cl}: 0.56-$ $0.75)$.

clinical practice patterns suggests that a bleeding risk index has limited utility for diagnostic and riskstratification purposes. Although the accuracy observed in our study was similar to what was achieved in other studies and for other bleeding risk tools (AUC: $068-$ $0.78)$, our interpretation differs $[3,13,14,17,20]$. The question for the clinician is whether the tool has good discrimination or the ability of the test to correctly classify those with and without the outcome. The area under the curve (AUC) represents the percentage of randomly drawn pairs for which a patient with and without the condition is correctly identified as such by the tool [19]. An AUC of 0.90 would achieve correct classification $90 \%$ of the time. The APACHE II score (AUC 0.98) is an example of a tool with high accuracy, great predictive value, and validation in various population samples [21, 22].

A diagnostic tool that has no clinical utility is one that is no better than chance. A tool with an AUC of 0.50 , for example, correctly classifies patients only $50 \%$ of the time. For the current validation study, among a wide spectrum of clinical patients, the BRS was disappointing, achieving an overall AUC of only 0.74 or a $74 \%$ probability of correctly classifying those with and without major bleeding. This finding and the corresponding poor likelihood ratios (unable to rule-in or rule-out), indicate that the tool has limited clinical utility for major bleeding.

Major bleeding was chosen as the primary outcome due to its relevance regarding outcome severity. Others have shown that the severity of bleeding is significantly associated with severity of patient outcomes [3, 23]. Minor bleeding (access site oozing, small hematoma, and other minor bleeding) has less clinical relevance for bleeding implications prior to and following discharge [23]. The inclusion of minor bleeding events can also generate less clinically relevant findings in validation studies. Compared to focusing on major bleeding events, inclusion of minor bleeding can over estimate sensitivity and under estimate specificity of the tool. Eliminating minor bleeding from the equation provides maximum accuracy estimates for bleeding of clinical relevance. The BRS in this population achieved a fair but not good discrimination result.

Furthermore, the tool performed less accurately among bivalirudin patients alone (AUC 0.65 compared to heparin AUC of 0.78). Because bivalirudin decreases the risk of bleeding for all patients, whether at low or high risk of bleeding, it is not surprising that 
the discrimination would be less than that for heparin patients. The tool would identify a greater rate of high risk patients among the bivalirudin group then among the heparin group for whom major bleeding does not occur. As expected, the predictive accuracy of the tool for patients given bivalirudin was very poor as it classifies many as high risk who are subsequently prevented from any major bleeding event. Treatment with bivalirudin following tool implementation differentially biases the high risk group with low bleeding rates, making retrospective validation skewed. This would explain the low predictability of the BRS that has been observed.

For validation purposes, the BRS requires adjustment for bivalirudin anticoagulation, which others identify as a limitation in previous validation studies [13, 17]. In addition, a physician clinical-selection effect renders validation problematic. Physicians preprocedurally select the very low and the high risk patients for prevention treatment. For risk stratification purposes, the actual utility of the BRS for the clinician occurs among intermediate risk groups. Yet, we observed poor predictive value with this category when validated in a real, world spectrum of patients (AUC: 0.58). Other studies examining in-hospital bleeding from $\mathrm{PCl}$ have performed validation of the BRS but our study is the first to perform the validation in a dataset independent of the data by which the tool was developed.

The strengths of our study include the validation among a large, independent dataset of patients across a wide spectrum of community hospital practices. We included only major bleeding events in order to focus findings on clinically significant patient outcomes. The data is current (2010-2012) and represent a wide range of clinical practices. Limitations include the low number of events in the low-risk group. However, when combined with the intermediate risk group accuracy did not improve substantively.

Overall, we observed fair but not good discrimination with the BRS for prediction of in-hospital bleeding following $\mathrm{PCl}$. For the intermediate and the combined risk groups, sensitivity was fair but specificity was low and the likelihood ratios were both indeterminate, even after controlling for anticoagulant therapy use. Based on these findings, the BRS can neither rule-in nor rule-out major bleeding episodes to any significant degree. The ultimate question is whether the consequences of using this tool will improve patient-oriented outcomes - no bleeding following $\mathrm{PCl}$. The utility of a bleeding risk index is low in terms of providing clinicians with a tool that can predict major bleeding among patients that are not at the extreme ends of risk, neither high nor very low risk. Sufficient evidence does not exist for an effective bleeding risk tool that is applied pre-procedure. Furthermore, bleeding risk tools that have been developed for predicting in-hospital major bleeding are less predictive and therefore less useful in the era of bivalirudin.

\section{CONCLUSION}

The bleeding risk score tool validated among an independent, current clinical spectrum of patients demonstrated low predictive value with findings similar to what others have reported. The current state of bleeding risk score tools provide little support for diagnostic utility in regards to major bleeding and therefore have limited clinical applicability.

\section{ACKNOWLEDGEMENT}

There was no association or relationship between authors and industry in the conduct, analysis, or writing of these study findings.

\section{REFERENCES}

[1] Abu-Assi E, Raposeiras-Roubin S, Lear P, et al. Comparing the predictive validity of three contemporary bleeding risk scores in acute coronary syndrome. Acute Cardiov Care 2012; 0: 1-10.

[2] Subherwal S, Back RG, Chen AY, et al. Baseline risk of major bleeding in non-ST-segment-elevation myocardial infarction: the CRUSADE (Can Rapid risk stratification of Unstable angina patients Suppress Adverse outcomes with Early implementation of the ACC/AHA Guidelines) Bleeding Score. Circulation 2009; 119: 1873-82. http://dx.doi.org/10.1161/CIRCULATIONAHA.108.828541

[3] Mehran R, Pocock S, Nikolsky E, et al. A risk score to predict bleeding in patients with acute coronary syndromes. JACC 2010; 55: 2556-66. http://dx.doi.org/10.1016/j.jacc.2009.09.076

[4] Hamm CW, Bassand JP, Agewall S, et al. ESC Guidelines for the management of acute coronary syndromes in patients presenting without persistent ST-segment elevation. Eur Heart J 2011; 32: 2999-54. http://dx.doi.org/10.1093/eurheartj/ehr236

[5] Matthews R, Peterson ED, Chen AY, et al. In-hospital major bleeding during ST-elevation and non-ST-elevation myocardial infarction care: derivation and validation of a model from the ACTION Registry-GWTG. Am J Cardiol 2011; 107: 1136-43.

http://dx.doi.org/10.1016/j.amjcard.2010.12.009

[6] Rao S, McCoy L, Spertus J, et al. An updated bleeding model to predict the risk of post-procedure bleeding among patients undergoing percutaneous coronary intervention. JACC: Cardiollntv 2013; 6: 897-904. http://dx.doi.org/10.1016/j.jcin.2013.04.016 
[7] Rao SV, O'Grady K, Pieper KS, et al. Impact of bleeding severity on clinical outcomes among patients with acute coronary syndromes. Am J Cardiol 2005; 96: 1200-206. http://dx.doi.org/10.1016/j.amjcard.2005.06.056

[8] Eikelboom JW, Mehta SR, Anand SS, Xie C, Fox KA, Yusuf S. Adverse impact of bleeding on prognosis in patients with acute coronary syndromes. Circulation 2006; 114: 774-82. http://dx.doi.org/10.1161/CIRCULATIONAHA.106.612812

[9] Moscucci M, Fox KA, Cannon CP, et al. Predictors of major bleeding in acute coronary syndromes: the Global Registry of Acute Coronary Events (GRACE). Eur Heart J 2003; 24: 1815-23. http://dx.doi.org/10.1016/S0195-668X(03)00485-8

[10] Baber U, Kovacic J, Kini AS, Sharma SK, Dangas G, and Mehran R. How serious a problem is bleeding in patients with acute coronary syndromes? Curr Cardiol Rep 2011; 13: 31219. http://dx.doi.org/10.1007/s11886-011-0192-3

[11] Kugelmass AD, Cohen DJ, Brown PP, Simon AW, Becker $\mathrm{ER}$, and Culler SD. Hospital resources consumed in treating complications associated with percutaneous coronary interventions. Am J Cardiol 2006; 97: 322-27. http://dx.doi.org/10.1016/j.amjcard.2005.08.047

[12] Manoukian SV. Predictors and impact of bleeding complications in percutaneous coronary intervention, acute coronary syndromes, and ST-segment elevation myocardial infarction. Am J Cardiol 2009; 104: 9C-15C. http://dx.doi.org/10.1016/j.amjcard.2009.06.020

[13] Mehta S, Fruckin A, Lindsey J, et al. Bleeding in patients undergoing percutaneous coronary intervention: The development of a clinical risk algorithm from the national cardiovascular data registry. Circ: Cardiovintv 2009; 2: 22229.

[14] Barra S, Providencia R, Caetano F, Almeida I, et al. BLEEDmyocardial infarction score: predicting mid-term postdischarge bleeding events. World J Cardiol 2013; 5: 196-206. http://dx.doi.org/10.4330/wjc.v5.i6.196

[15] Nikolsky E, Mehran R, Dangas G, et al. Development and validation of a prognostic risk score for major bleeding in patients undergoing percutaneous coronary intervention via the femoral approach. Eur Heart J 2007; 28: 1936-45. http://dx.doi.org/10.1093/eurheartj/ehm194
[16]

Pisters R, Lane DA, Nieuwlaat R, de Vos CB, Crijins HJ, Lip GY. A novel user-friendly score (HAS-BLED) to assess 1year risk of major bleeding in patients with atrial fibrillation: the EURO Heart Survey. Chest 2010; 138: 1093-100.

http://dx.doi.org/10.1378/chest.10-0134

[17] Rao S, McCoy L, Spertus J, et al. An updated bleeding model to predict the risk of post-procedure bleeding among patients undergoing percutaneous coronary intervention. JACC: Cardiollntv 2013; 6: 897-904. http://dx.doi.org/10.1016/j.jcin.2013.04.016

[18] A-Levey AS, Stevens LA, Schmid CH, et al. CKD-DPI (Chronic Kidney Disease Epidemiology Collaboration). A new equation to estimate glomerular filtration rate. Ann Intern Med 2009; 150(9): 604-12. http://dx.doi.org/10.7326/0003-4819-150-9-200905050$\underline{00006}$

[19] Hanley JA, McNeil BJ. The meaning and use of the area under a receiver operating characteristic (ROC) curve. Radiology 1982; 143: 29-36.

[20] Ducrocq G, Wallace JS, Baron G, et al. Risk score to predict serious bleeding in stable outpatients with or at risk of atherothrombosis. Eur Heart J 2010; 31: 1257-65. http://dx.doi.org/10.1093/eurheartj/ehq021

[21] Knaus WA, Wagner DP, Draper EA, et al. The APACHE IIIPrognositc System: risk prediction of hospital mortality for critically ill hospitalized adults. CHEST 1991; 100: 1619-36. http://dx.doi.org/10.1378/chest.100.6.1619

[22] Joe $\mathrm{BH}$, Jo U, Kim HS, et al. APACHE II score, rather than cardiac function, may predict poor prognosis in patients with stress-induced cardiomyopathy. J Korean Med Sci 2012; 27 : 52-57. http://dx.doi.org/10.3346/jkms.2012.27.1.52

[23] White HD, Aylward PE, Gallo R, et al. STEEPLE Investigators. Hematomas of at least $5 \mathrm{~cm}$ and outcomes in patients undergoing elective percutaneous coronary intervention: insights from the SafeTy and Efficacy of Enoxaparin in $\mathrm{PCl}$ patients, an internationaL randomized Evaluation (STEEPLE) trial. Am Heart J 2010; 159: 110-6. http://dx.doi.org/10.1016/j.ahj.2009.10.034

(C) 2014 Dobies et al.; Licensee Lifescience Global.

This is an open access article licensed under the terms of the Creative Commons Attribution Non-Commercial License (http://creativecommons.org/licenses/by-nc/3.0/) which permits unrestricted, non-commercial use, distribution and reproduction in any medium, provided the work is properly cited. 